\title{
THE EFFECT OF BLACK CUMIN SEED OIL CONSUMPTION ON CLOTTING TIME, BLEEDING TIME, AND PLATELET COUNTS IN HEALTHY-SMOKER VOLUNTEERS
}

\author{
AKROM AKROM ${ }^{1,2^{*}}$, NELLY RATNASARI ${ }^{1}$, DJATUN NIQOTAINI ${ }^{1}$
}

1Pharmacology and Clinical Pharmacy Department, Pharmacy Faculty, Universitas Ahmad Dahlan, Yogyakarta, Indonesia, ${ }^{2}$ Ahmad Dahlan Drug Information and Research Center, Universitas Ahmad Dahlan, Yogyakarta, Indonesia

"Email: akrom@pharm.uad.ac.id

Received: 01 Sep 2020, Revised and Accepted: 09 Oct 2020

\section{ABSTRACT}

Objective: The objective of the study was to determine the effect of consumption of black cumin seed oil (BCSO) on platelet count, clotting time (CT), and bleeding time (BT) in healthy-smoker volunteers (HSV).

Methods: Participants were 39 healthy male smokers aged 18-66 y. Participants were divided into four groups randomly. The treatment group received BCSO for thirties days in $3 \times 1,3 \times 2$, and $3 \times 3$ capsules/day doses. The placebo group received a placebo preparation. We measured CT, BT, and platelet count on day 31. An analysis of the mean difference between CT, BT, and platelet counts was performed using one-way ANOVA.

Result: The results showed that the CT, BT, and platelet counts in all groups were within normal. Consumption of BCSO for $30 \mathrm{~d}$ did not affect CT, BT, and platelet counts of HSV. The results of the analysis of the mean difference test between groups of CT, BT, and platelet counts indicated that there was no difference with $\mathrm{p}>0.05$.

Conclusion: We concluded that the 30-day BCSO consumption did not affect the CT, BT, and platelet count values in HSV.

Keywords: Black cumin seed oil, Hemostasis, Healthy-smoker volunteer, Open-label clinical trial

(C) 2021 The Authors. Published by Innovare Academic Sciences Pvt Ltd. This is an open access article under theCC BY license(http://creativecommons.org/licenses/by/4.0/) DOI: http://dx.doi.org/10.22159/ijap.2021.v13s2.17 Journal homepage: https://innovareacademics.in/journals/index.php/ijap

\section{INTRODUCTION}

Smoking is one of the public health problems in Indonesia [1]. Cigarettes are addictive, toxic, carcinogenic, and immunosuppressant $[2,3]$. Cigarette exposure is associated with an increased incidence of hypertension, diabetes mellitus, cardiac ischemia, stroke, and kidney failure [4-7]. The addictive nature of cigarettes comes from the nicotine they contain. After cigarette smoke is inhaled, nicotine will reach the brain $[8,9]$. Smoking is one of the factors that can cause an increase in plasma homocysteine levels and radical reactive in the body $[10,11]$. Homocysteine affects several factors involved in the blood clotting cascade, such as decreasing anti-thrombin activity, accelerating thrombus formation, and increasing platelet aggregation [12]. Homocysteine also suppresses natural thrombolysis by reducing tissue plasminogen activator [13]. Homocysteine causes damage to the endothelium [14]. This damage causes a decrease in the production of prostacyclin, which can cause thrombus to form in the vascular system, resulting in thrombosis $[11,15]$. Clotting Time (CT) and Bleeding time (BT) are routine examinations to determine the intrinsic and extrinsic coagulation pathways. Platelets are blood cells that are responsible react to bleeding from blood vessel injury by clumping, thereby initiating a blood clot. Platelets in a resting state circulate in the bloodstream. Platelets will undergo rapid deformation at the injury site in the event of a vascular injury, where they roll over, stick together, and collect to stop bleeding with thrombus formation $[16,17]$. Smoking habits are associated with coagulation factors malfunctions [18]. Smoking habits are also thought to be related to changes in CT and BT values.

Black cumin (Nigella sativa L.) is one of the Nigella genus [19]. Nigella sativa is useful for increasing stamina and body defense [20], antioxidants and anti-aging [21], anti-infection [22] and prevention of degenerative diseases (cancer, diabetes mellitus, stroke, hypertension) [23]. One of the most important active compounds contained in black cumin is thymoquinone [24]. Thymoquinone is anti-oxidative [25], immunomodulatory, chemopreventive, and antiinflammatory [26, 27]. Antioxidants can inhibit oxidative stress and reduce the potential for damage to cell structure and function [28]. Tobacco smoking causes oxidative stress [29]. Oxidative stress is a condition in which the formation of reactive oxygen species (ROS) and long-term antioxidant defense systems is not balanced in the body [30,31]. Oxidative stress can cause various disorders such as cardiovascular disease, diabetes, rheumatoid arthritis, cancer, and neurodegenerative disorders [32]. Antioxidants are responsible for the body's mechanisms for fighting disease pathologies related to the free radical attack [33]. Thymoquinone and antioxidants agents are believed to play an essential role in the body's defense system against radical reactive and maintain overall body health [34]. Consumption of BCSO is thought to inhibit the increase in platelet counts and normalize CT and BT values in smokers. The purpose of this study was to determine the effect of administration of BCSO for $30 \mathrm{~d}$ on the platelet count, clotting time, and bleeding time in healthy-smokers volunteers.

\section{MATERIALS AND METHODS}

\section{Types and research design}

In this study, the experimental design used was Open-Label Randomized Controlled Trial. Three BCSO dosage ratings were given, namely $3 \times 1 ; 3 \times 2$; and $3 \times 3$ capsules/day. We carried out the research protocol following the Declaration of Helsinki, where the research protocol had been reviewed and had obtained ethics worthy statements from the UAD research ethics committee.

Materials, tools, and subjects

The research materials included BCSO capsules containing standardized BCSO and placebo preparations. The placebo and BCSO capsules are prepared by the traditional medicine industry certified by the National Agency of Drug and Food Control. The equipment needed in the research includes a weight scale, thermometer, tensimeter, test tube, stopwatch, and hemato analyzer.

Inclusion criteria were healthy volunteers and active smokers. Men aged $>18$ y and willing to become participants (as evidenced by a willingness to fill and sign the informed consent). Exclusion criteria were volunteer smokers who suffered from chronic diseases, missed medication schedules, and used supplements other than BCSO. Participants who experienced an incidence of side effects to be 
excluded from the study. Following phase 1 research guidelines, this study involved 39 participants.

\section{Participant recruitment for research procedures}

Prospective subjects who meet the inclusion criteria are asked to participate in the study by signing the informed consent after explaining the objectives, benefits, and research procedures and consequences and compensation as participants. Prospective participants who have signed the informed consent are then subjected to a physical examination to determine the clinical condition and physical health status by the Puskesmas doctor.

\section{The assignment in the experimental group}

Placement of participants into the test group was done randomly using the manual method (coins). Participants were divided into four groups. The pharmacist stores the random numbers were resulting from the randomization process. Group I, namely the control/placebo group, subjects received a soft capsule without BCSO. Group II, III, and IV, the subjects received BCSO capsules at a dose of $3 \times 1,3 \times 2$, and $3 \times 3 /$ day. BCSO is a soft capsule containing BCSO, where one capsule contains $\pm 450 \mathrm{mg}$ of BCSO (excluding capsule shell).

\section{Implementation of the provision of BCSO and monitoring}

Both placebo and BCSO are given for $30 \mathrm{~d}$, which are consumed regularly. Monitoring the condition of the participants is carried out twice a week through direct interviews with residents' houses. Monitoring the participant's situation includes clinical conditions (blood pressure, respiration, temperature, and pulse), complaints, and effects that arise after administration, including side effects and ascertaining the amount of medication remaining and supplementing the case report form (CRF).

\section{Data retrieval}

On the 31st day, participants/volunteers have collected again for blood sampling for complete blood counts, clinical examination, and education and dissemination on the need for a healthy lifestyle. The researcher presented the first laboratory examination (pretreatment), providing clinical interpretation and recommendations for follow-up. We sent the blood to Nur Hidayah Hospital for platelet counts using a hemato-analyzer. We determined clotting time using the Lee-white method and bleeding time using the Ivy method.

\section{Data analysis}

Participant characteristics are presented descriptively in the form of a percentage. We determined the difference in the proportion of demographic and smoking habits characteristics between groups using the chi-square. We performed a mean difference test between groups for the mean of CT, BT, and platelet count using the one-way ANOVA, with a $95 \%$ confidence level.

\section{RESULTS AND DISCUSSION}

\section{Characteristics of the subject}

Based on research conducted on men over $18 \mathrm{y}$ old at PHC Jetis 1 Bantul Yogyakarta (PJ1BY), where BCSO effects on clotting time and bleeding time in smokers. This research was conducted by filling out the nutritional recall form. Respondents have signed informed consent before recruited, and the ethics commission has approved all protocols.

It is known that the Subjects who consumed the BCSO were in the age range $<60 \mathrm{y}$, as many as 39 volunteers. Table 1 showed the demographic characteristics of the Subject. Most of the participants have a junior high school education, with a livelihood as masons and carpenters. Most of the participants smoked less than ten cigarettes/day and had lasted 10-30 y.

Table I: Distribution of characteristics of healthy-smoker volunteers (HSV) who consume BCSO in the working area of PJ1BY in september-october 2019

\begin{tabular}{|c|c|c|c|c|c|c|}
\hline Characteristic & Placebo & BCS0 3X1 & BCSO 3X2 & BCSO 3X3 & Total & Significance (2-sided) \\
\hline \multicolumn{7}{|l|}{ 1. Age } \\
\hline$>60 \mathrm{Y}$ & 0 & 0 & 2 & 0 & 2 & 0.19 \\
\hline$<60 \mathrm{Y}$ & 9 & 9 & 10 & 9 & 37 & \\
\hline Total & 9 & 9 & 12 & 9 & 39 & \\
\hline \multicolumn{7}{|l|}{ 2. Education } \\
\hline Elementary & 0 & 0 & 4 & 2 & 6 & 0.25 \\
\hline Yunior Hight school & 2 & 0 & 2 & 1 & 5 & \\
\hline Senior height school & 7 & 7 & 5 & 5 & 24 & \\
\hline University & 0 & 2 & 1 & 1 & 4 & \\
\hline Total & 9 & 9 & 12 & 9 & 39 & \\
\hline \multicolumn{7}{|l|}{ 3. Job } \\
\hline Labor & 5 & 2 & 6 & 5 & 18 & 0.37 \\
\hline Teacher & 0 & 1 & 0 & 0 & 1 & \\
\hline Students a & 0 & 0 & 0 & 1 & 1 & \\
\hline Retired & 0 & 1 & 0 & 0 & 1 & \\
\hline Farmer & 0 & 0 & 0 & 1 & 1 & \\
\hline private & 4 & 5 & 6 & 2 & 17 & \\
\hline Total & 9 & 9 & 12 & 9 & 39 & \\
\hline \multicolumn{7}{|l|}{ 4. Smoking habit type } \\
\hline Cigarette smoking & 9 & 9 & 11 & 9 & 38 & 0.51 \\
\hline Electrical smoking & 0 & 0 & 1 & 0 & 1 & \\
\hline Total & 9 & 9 & 12 & 9 & 39 & \\
\hline \multicolumn{7}{|l|}{ 5. Number of stick/day } \\
\hline$<10$ stick & 5 & 7 & 3 & 3 & 21 & 0.29 \\
\hline$>10$ stick & 4 & 2 & 6 & 6 & 18 & \\
\hline Total & 9 & 9 & 12 & 9 & 39 & \\
\hline \multicolumn{7}{|c|}{ 6. Duration of smoking (year) } \\
\hline$<10 y$ & 2 & 4 & 2 & 2 & 10 & 0.53 \\
\hline $10-30 y$ & 7 & 4 & 7 & 5 & 23 & \\
\hline$>30 y$ & 0 & 1 & 3 & 2 & 6 & \\
\hline Total & 9 & 9 & 12 & 9 & 39 & \\
\hline
\end{tabular}

The clinical conditions of participants before administering BCSO are presented in table 2 . Based on the data in table 2, it is known that the participants' blood pressure, temperature, pulse, BMI, urea, creatinine, blood sugar, cholesterol, and triglycerides were within normal limits. There was no difference in clinical parameters between test groups ( $\mathrm{p}>0.05)$. 
Table 2: Participants' clinical condition before receiving BCSO, participants were healthy male smokers

\begin{tabular}{|c|c|c|c|c|c|c|}
\hline \multirow[t]{2}{*}{ Parameter } & \multicolumn{5}{|c|}{ Experimental groups } & \multirow[t]{2}{*}{$\mathbf{P}$} \\
\hline & Placebo $(n=9)$ & BCSO 3x1 (n=9) & BCSO 3x2 (n=12) & BCSO 3x3 (n=9) & Total $(n=39)$ & \\
\hline SBP & $133.14 \pm 17.15$ & $143.14 \pm 37.52$ & $140.25 \pm 19.71$ & $135.00 \pm 9.48$ & $137.97 \pm 22.30$ & 0.85 \\
\hline DBP & $86.57 \pm 8.34$ & $89.29 \pm 20.77$ & $86.37 \pm 10.47$ & $80.57 \pm 7.32$ & $85.72 \pm 12.50$ & 0.86 \\
\hline Hearth Rate & $83.29 \pm 41.19$ & $83.42 \pm 40.88$ & $81.13 \pm 6.48$ & $83.71 \pm 8.64$ & $82.59 \pm 8.91$ & 0.52 \\
\hline Temperature & $35.28 \pm 0.49$ & $35.85 \pm 0.69$ & $35.64 \pm 0.52$ & $35.86 \pm 0.38$ & $35.67 \pm 0.65$ & 0.51 \\
\hline BMI & $23.57 \pm 3.95$ & $22.71 \pm 3.30$ & $25.00 \pm 5.75$ & $25.71 \pm 6.68$ & $24.24 \pm 4.95$ & 019 \\
\hline Ureum & $33.57 \pm 11.08$ & $33.54 \pm 6.57$ & $28.59 \pm 5.79$ & $28.74 \pm 4.96$ & $31.11 \pm 7.53$ & 0.21 \\
\hline creatinin & $1.17 \pm 0.20$ & $1.09 \pm 0.099$ & $1.04 \pm 0.08$ & $1.06 \pm 0.11$ & $1.09 \pm 0.14$ & 0.76 \\
\hline Blood glucose & $131.8 \pm 915.60$ & $145.20 \pm 53.12$ & $166.80 \pm 46.59$ & $131.89 \pm 24.84$ & $144.58 \pm 40.15$ & 0.14 \\
\hline Triglyceride & $172.67 \pm 77.59$ & $150.20 \pm 76.39$ & $164.70 \pm 60.83$ & $188.33 \pm 151.63$ & $168.37 \pm 93.75$ & 0.53 \\
\hline cholesterol & $159.22 \pm 41.08$ & $151.30 \pm 29.05$ & $152.00 \pm 25.56$ & $154.78 \pm 26.60$ & $154.18 \pm 29.86$ & 0.48 \\
\hline
\end{tabular}

Note: $\mathrm{SBP}=$ systolic blood pressure; $\mathrm{DBP}=$ diastolic blood pressure; BMI=body mass index; BCSO=black cumin seed oil; Data were given in mean+SD

\section{BCSO effects on the number of platelets, Clotting time (CT), and blooding time (BT)}

The impact of BCSO consumption for $30 \mathrm{~d}$ on platelet count, CT, and BT in healthy volunteers-smokers are presented in table 3.

Average values in healthy humans are: Clotting Time $=9-15 \mathrm{~min}$ and Bleeding Time $=1-5$ min. Based on table 3, it is known that the CT, BT, and platelet count values in the four test groups were within normal limits.
The smoking habit of the participants did not affect the CT and BT values and the number of platelets. There was a decrease in platelet count and BT value in the treatment group compared to the placebo group, but it was not statistically significant ( $p>0.05$ ). Consumption of BCSO for $30 \mathrm{~d}$ did not affect CT and BT healthy volunteer smokers in the placebo group with the treatment group. There was no difference in the mean CT and BT between treatment groups ( $p>0.05$ ). Consumption of BCSO for $30 \mathrm{~d}$ by healthy volunteer smokers did not affect CT/BT.

Table 3: The average value and standard deviation of clotting time, bleeding time, and number of platelet for healthy_smoking volunteers (HSV) who consume BCSO in the work area of PJ1BY for the period September-October 2019

\begin{tabular}{llll}
\hline Experimental group (n) & Clotting time & Bleeding time & Platelet count \\
\hline Placebo $(n=9)$ & $10.89 \pm 1.05$ & $3.22 \pm 0.44$ & $243.22 \pm 40.01$ \\
BCSO 3X1 $(n=9)$ & $11.89 \pm 1.61$ & $3.22 \pm 0.44$ & $208.33 \pm 39.52$ \\
BCSO 3X2 $(n=12)$ & $10.75 \pm 1.71$ & $3.17 \pm 0.38$ & $237.75 \pm 47.56$ \\
BCSO 3X3 $(n=9)$ & $10.44 \pm 1.66$ & $3.11 \pm 0.33$ & $245.44 \pm 68.58$ \\
Total $(n=39)$ & $10.97 \pm 1.58$ & $3.18 \pm 0.38$ & $236.05 \pm 50.43$ \\
P & 0.31 & 0.21 & 0.25 \\
\hline
\end{tabular}

Note: BCSO=black cumin seed oil; capsule of BCSO = $450 \mathrm{mg}$ of BCSO without a shell; One placebo capsule = 450 mg placebo without shell; Data were given in mean \pm SD

\section{DISCUSSION}

All volunteers are men, mostly as construction workers and casual daily laborers, who have graduated from elementary school education and are in the productive age group (table 1). The clinical and chemical parameters for the participants are in expected value (table 2). The CT and BT of all test groups were within normal limits (table 3). Based on the data in Tables 2 and 3, it is known that the smoking habits of volunteers have not affected the clinical parameters and the CT, BT, and platelet count values. Data from this study are not following the results of previous studies [35,36]. Research had shown that acute smoking could change the platelet count and induce endothelial damage. The effect of smoking on the clotting time and bleeding time in healthy men was a shortening of clotting time and bleeding time in moderate and heavy smokers [37]. Elkhalifa's (2018) study, which examined the effect of cigarette smoking on the coagulation screening test and platelet counts in a Sundanese male adults population, that the average prothrombin time (PT) was significantly shorter in smokers when compared to non-smokers [35]. Smoking has been identified as a principal underlying etiology for the occurrence and progression of cardiovascular diseases, inflammatory disorders, and oxidative stress stimulation [38]. Cigarette smoking's crucial role in disrupting platelet activation and aggregation, as well as other coagulation processing components leading to thrombotic formations, has been recently suggested [36]. The pathophysiological effects of cigarette smoking on platelet activation have been recently investigated [10, 39]. Until now, the impact of smoking on the platelets is not all clear. Previous research has shown that acute smoking can alter platelet counts and cause endothelial damage [29]; however, in other studies, smoking did not induce platelet aggregation as a result of stimulation by effects such as adenosine diphosphate (ADP), epinephrine, and collagen, has been recently suggested [40]. We apologize that some of the factors causing the difference in Our results may be include differences in subject characteristics, lifestyle, and smoking intensity. Participants in this study were construction workers with a lot of physical activity and with a mild to the moderate smoking habit. El khalifa's research involved participants with moderate to severe smoking habits [35].

Based on the data in table 3, it is known that the consumption of BCSO for $30 \mathrm{~d}$ did not affect the platelet count, CT, and BT values. There was no difference in the number of platelets between the placebo group and the treatment group ( $p>0.05)$. Based on table 3 , it is known that the platelet count, CT, and BT values are within normal limits or in homeostatic conditions [41], and consumption of BCSO for $30 \mathrm{~d}$ does not change homeostasis. Based on this evidence, the consumption of BCSO for $30 \mathrm{~d}$ did not alter the homeostasis of healthy-smoker volunteers. The results of this study are following previous research data, which proves that consumption of BCSO for 20 in healthy volunteers is safe and can be tolerated [42].

There are several limitations of this study, i.e. (i) we couldn't control the food consumed by the participants, (ii) the number of participants involved was also still limited, and (iii) loose variations in physical activity and lifestyle of participants, so that many confounding factors are difficult to control.

\section{CONCLUSION}

Consumption of black cumin seed oil for $30 \mathrm{~d}$ in Healthy-smoker volunteers did not affect the platelet count and the value of clotting time and bleeding time.

\section{ACKNOWLEDGMENT}

The research team would like to thank and give a tremendous appreciation to all participants who have been willing to volunteer 
in this study. We also provide our gratitude to the leadership and staff at Puskesmas Jetis I, the Head of Blawong Hamlet, and the head of the Sindet Hamlet. They have supported and facilitated this research. Researchers also give appreciation and gratitude to the Ministry of Research, Technology, and Higher Education for providing research assistance.

\section{FUNDING}

Ministry of Research and Technology/National Research and Innovation Agency (KEMENRISTEK/BRIN) single year 2020 budget year number: PTM-036/SKPPTT/IPPM UAD/VI/2020.

\section{AUTHORS CONTRIBUTIONS}

All authors discussed the results and contributed to the final manuscript.

\section{CONFLICT OF INTERESTS}

Authors declare no conflict of interest

\section{REFERENCES}

1. Semba RD, Kalm LM, De Pee S, Ricks MO, Sari M, Bloem MW. Paternal smoking is associated with increased risk of child malnutrition among poor urban families in Indonesia. Public Health Nutr 2007;10:7-15.

2. Middlekauff HR, Park J, Moheimani RS. Adverse effects of cigarette and noncigarette smoke exposure on the autonomic nervous system: mechanisms and implications for cardiovascular risk. J Am Coll Cardiol 2014;64:1740-50.

3. Thorne D, Leverette R, Breheny D, Lloyd M, McEnaney S, Whitwell J, et al. Genotoxicity evaluation of tobacco and nicotine delivery products: part one. Mouse lymphoma assay. Food Chem Toxicol 2019;132:110584.

4. Chan SMH, Selemidis S, Bozinovski S, Vlahos R. Pathobiological mechanisms underlying metabolic syndrome (MetS)in chronic obstructive pulmonary disease (COPD): clinical significance and therapeutic strategies. Pharmacol Ther 2019;198:160-88.

5. Hidayati TI, Fatimah SN, Iskandar SH. Normal fasting blood sugar levels and medication adherence improve the quality of life of type 2 diabetes mellitus patients in primary health facilities. Asian J Pharm Clin 2018;11:472-7.

6. Staplin N, Haynes R, Herrington WG, Reith C, Cass A, Fellström $\mathrm{B}$, et al. Smoking and adverse outcomes in patients with CKD: The study of heart and renal protection (SHARP). Am J Kidney Dis 2016;68:371-80.

7. Nagasawa Y, Yamamoto R, Rakugi H, Isaka Y. Cigarette smoking and chronic kidney diseases. Hypertens Res 2012;35:261-5.

8. Kalkhoran S, Benowitz NL, Rigotti NA. Prevention and treatment of tobacco use: JACC health promotion series. J Am Coll Cardiol 2018;72:1030-45.

9. Koukouli F, Changeux JP. Do nicotinic receptors modulate highorder cognitive processing? Trends Neurosci 2020;43;550-64.

10. Ibrahim H, Schutt RC, Hannawi B, DeLao T, Barker CM, Kleiman NS. Association of immature platelets with adverse cardiovascular outcomes. J Am Coll Cardiol 2014;64:2122-9.

11. Hirmerova J. Homocysteine and venous thromboembolism-is there any link? Cor Vasa 2013;55:248-58.

12. De Farias Leal AA, Palmeira AC, Almeida De Castro GM, Da Silva Simoes MO, Ramos AT, Muniz Medeiros CC. Homocysteine: cardiovascular risk factor in children and adolescents? Rev da Assoc Medica Bras 2013;59:622-8.

13. Liu L, Cao J, Fan L, Hu G, Hu Y, Zhu B, et al. Prevalence and risk factors for aspirin resistance in elderly patients with type 2 diabetes. Int J Gerontol 2011;5:112-6.

14. Hainsworth AH, Yeo NE, Weekman EM, Wilcock DM. Homocysteine, hyperhomocysteinemia and vascular contributions to cognitive impairment and dementia (VCID). Biochim Biophys Acta Mol Basis Dis 2016;1862:1008-17.

15. Alkhoury K, Parkin SM, Homer Vanniasinkam S, Graham AM. Chronic homocysteine exposure upregulates endothelial adhesion molecules and mediates leukocyte: endothelial cell interactions under flow conditions. Eur J Vasc Endovasc Surg 2011;41:429-35.

16. Gresele P. Platelets in hematologic and cardiovascular disorders: a clinical handbook. USA: Cambridge University Press; 2008. p. 511.
17. Lincoff AM. Platelet glycoprotein IIb/IIIa Inhibitors in cardiovascular disease $2^{\text {nd }}$ Ed. Berlin: Springer Science and Business Media; 2003.

18. Pedersen KM, Colak Y, Ellervik C, Hasselbalch HC, Bojesen SE, Nordestgaard BG. Smoking and increased white and red blood cells: a mendelian randomization approach in the copenhagen general population study. Arterioscler Thromb Vasc Biol 2019;39:965-77.

19. Al-Quorain AA, Bamosa AO, Pal K, Durmaz MS, Yilmaz S, Keven A, et al. Nigella sativa. Saudi J Med Med Sci 2015;3:1-6.

20. Akrom, Mustofa. Black cumin seed oil increases phagocytic activity and secretion of IL-12 by macrophages. Biomed Res 2017;28:5241-6.

21. Krishnan N, Muthukrishnan S. Effect of Nigella sativa seed extract on carbon tetrachloride-induced hepatotoxicity in rats. J Acute Med 2012;2:107-13.

22. Bourgou S, Pichette A, Marzouk B, Legault J. Bioactivities of black cumin essential oil and its main terpenes from Tunisia. South African J Bot 2010;76:210-6.

23. Azzubaidi MS, Mizher H, Alattraqchi AG. Hypotensive activity of thymoquinone in normotensive rats and its receptor mechanisms. Int J Pharm Pharm Sci 2017;9:216-8.

24. Yimer EM, Tuem KB, Karim A, Ur-Rehman N, Anwar F. Nigella sativa L.(black cumin): a promising natural remedy for wide range of illnesses. Evidence Based Compl Alt Med 2019;2019:1-16.

25. Nithya G, Mani R, Sakthisekaran D. Oral administration of thymoquinone attenuates Benzo (a) pyrene induced lung carcinogenesis in male swiss albino mice. Int J Pharm Pharm Sci 2014;6:260-3

26. Hidayati T, Akrom, Indrayanti, Sagiran. Chemopreventive effect of black cumin seed oil (BCSO) by increasing p53 expression in dimethylbenzanthracene (DMBA)-induced sprague dawley rats. Res J Chem Environ 2019;23:140-8.

27. Salem ML. Immunomodulatory and therapeutic properties of the Nigella sativa L. seed. Int Immunopharmacol 2005;5:1749-70.

28. Burits M, Bucar F. Antioxidant activity of Nigella sativa essential oil. Phyther Res 2000;14:323-8.

29. Chełchowska M, Ambroszkiewicz J, Gajewska J, Mazur J, Lewandowski L, Reśko Zachara $\mathrm{M}$, et al. Influence of active exposure to tobacco smoke on nitric oxide status of pregnant women. Int J Environ Res Public Health 2018;15:2719.

30. Fajar DR, Akrom, Darmawan E. The influence of black cumin seed oil therapy with dosage of $1.5 \mathrm{ml} /$ day and $3 \mathrm{ml} /$ day to interleukin-21 (IL-21) expression of the patients with metabolic syndrome risk. IOP Conf Ser Mater Sci Eng 2017;259:012012.

31. Hidayati T, Akrom, Indrayanti, Sagiran. Evaluation of the black cumin seed oil role (BCSO) on a decline in eNOS expression and plasma NO levels: initial studies kemopreventive BCSO for lung cancer. Int J Biosci Biochem Bioinforma 2017;7:162-8.

32. Sack MN, Fyhrquist FY, Saijonmaa OJ, Fuster V, Kovacic JC. Basic biology of oxidative stress and the cardiovascular system: part 1 of a 3-part series. J Am Coll Cardiol 2017;70:196-211.

33. Romieu I, Castro Giner F, Kunzli N, Sunyer J. Air pollution, oxidative stress and dietary supplementation: a review. Eur Resp J 2008;31:179-97.

34. Farkhondeh T, Samarghandian S, Borji A. An overview on cardioprotective and anti-diabetic effects of thymoquinone. Asian Pac J Trop Med 2017;10:849-54.

35. Elkhalifa A. Effects of cigarette smoking on coagulation screening tests and platelet counts in a sudanese male adults population. Saudi Med J 2018;39:897-901.

36. Lowery CL, Elliott C, Cooper A, Hadden C, Sonon RN, Azadi P, et al. Cigarette smoking-associated alterations in serotonin/adrenalin signaling pathways of platelets. J Am Heart Assoc 2017;6:6-8.

37. Malenica M, Prnjavorac B, Bego T, Dujic T, Semiz S, Skrbo S, et al. Effect of cigarette smoking on haematological parameters in healthy population. Med Arch 2017;71:132-6.

38. Gonçalves RB, Coletta RD, Silverio KG, Benevides L, Casati MZ, Da Silva JS, et al. Impact of smoking on inflammation: overview of molecular mechanisms. Inflamm Res 2011;60:409-24.

39. Morita H, Ikeda H, Haramaki N, Eguchi H, Imaizumi T. Only twoweek smoking cessation improves platelet aggregability and 
intraplatelet redox imbalance of long-term smokers. J Am Coll Cardiol 2005;45:589-94.

40. Zulkifli MH, Viswenaden P, Jasamai M, Azmi N, Yaakob NS Potential roles of 5-HT 3 receptor (5-HT $3 \mathrm{R}$ ) antagonists in modulating the effects of nicotine. Biomed Pharmacother 2019;112:108630.
41. Bounous DI, Wyatt RD, Gibbs PS, Kilburn JV, Depart-CFQ. Normal hematologic and serum biochemical reference intervals for juvenile wild turkeys. J Wild Dis 2000;36:393-6.

42. Akrom A, Darmawan E. Tolerability and safety of black cumin seed oil (BCSO) administration for $20 \mathrm{~d}$ in healthy subjects. Biomed Res 2017;28:4196-201. 